\title{
EMPRESA INDIVIDUAL DE RESPONSABILIDADE LIMITADA (EIRELI): CONSIDERAÇÕES GERAIS COM ENFOQUE NA NATUREZA JURÍDICA DO NOVO INSTITUTO, INTRODUZIDO PELA LEI No $12.441 / 2011$
}

\section{Ana Paula de Bittencourt ${ }^{1}$}

Resumo: O presente artigo versa sobre as inovações trazidas pela Lei $n^{\circ} 12.441 / 11$ ao Código Civil Brasileiro, inserindo uma nova modalidade de pessoa jurídica de direito privado, Empresa Individual de Responsabilidade Limitada (EIRELI). A referida Lei dispõe sobre as características específicas desse instituto, quais sejam: a titularidade, a integralização do capital, o nome empresarial, a constituição e demais formalidades a serem observadas pelo empresário que deseja enquadrar-se em tal categoria, bem como sua administração. A novel tipificação revoluciona o ramo do direito empresarial, a ponto de dividir opiniões a respeito da sua natureza jurídica. Empresa Individual, Sociedade Unipessoal ou de natureza jurídica sui generis, o fato é que a EIRELI representa um avanço no ordenamento jurídico brasileiro. Finalmente, tratar-se-á sobre a compatibilidade do instituto com a Microempresa (ME) e a Empresa de Pequeno Porte (EPP) e a incompatibilidade com a atividade advocatícia.

Palavras-chave: Direito empresarial. EIRELI. Empresa Individual. Responsabilidade limitada. Lei $n^{\circ} 12.441 / 11$.

1 Bacharel em Direito - UNISUL. Aluna do Módulo II da ESMESC. E-mail: anabittencourt13@hotmail.com 


\section{INTRODUÇÃO}

O presente artigo tem como objetivo geral apresentar os aspectos trazidos pela Lei $n^{\circ} 12.441 / 2011$, a qual introduziu no ordenamento jurídico brasileiro a Empresa Individual de Responsabilidade Limitada (EIRELI).

A nova pessoa jurídica de direito privado, acrescentada ao art. 44 do Código Civil, baseasse na Instrução Normativa $n^{\circ}$ 117/2011, que aprova o Manual de Atos de Registro da Empresa Individual de Responsabilidade Limitada, documento fundamental para a constituição e administração da EIRELI.

Analisa também, a capacidade para ser titular desta modalidade empresarial, a integralização do capital, o nome empresarial e a administração da empresa.

Especificamente, objetiva enfocar na natureza jurídica, deveras controvertida, do novo instituto inserido no código civil brasileiro, para uns, Empresa Individual, para outros, Sociedade Unipessoal, não bastando à divergência, há quem defenda a natureza jurídica sui generis da EIRELI.

Por fim, abordar-se-á sobre a compatibilidade da EIRELI com a Microempresa (ME) e a Empresa de Pequeno Porte (EPP) e a sua incompatibilidade com a atividade da advocacia.

\section{ANOTAÇÕES PRÉVIAS}

Vejamos os dados históricos apurados em pesquisa realizada por Diogo Jorge Favacho dos Santos (2011):

No começo dos anos 1980, iniciou-se a discussão para a criação da EIRELI no âmbito do Programa Nacional de Desburocratização, comandada pelo então ministro Hélio Beltrão.

Novamente, na década de 1990, no âmbito do Programa Federal de Desregulamentação, o tema voltou a ser proposto, com o objetivo de permitir ao empresário individual, explorar atividade econômica sem colocar em risco seus bens particulares.

Ontigo anteprojeto da nova lei das sociedades limitadas, 
elaborado por juristas coordenados por Arnold Wald continha, então, proposta de criação da figura da "empresa individual de responsabilidade limitada”, mas ele foi deixado de lado em virtude da tramitação do novo Código Civil.

Cabe ressaltar que o tema não é inédito no mundo jurídico, pois não são poucos os países que instituíram a empresa individual de responsabilidade limitada, como por exemplo: França, Espanha, Portugal, Itália, Bélgica, Países Baixos, Alemanha, Reino Unido, Dinamarca e, na América do Sul, no Chile.

Enfim, no ano de 2011 é sancionada a Lei 12.441, que trata da Empresa Individual de Responsabilidade Limitada (EIRELI).

$O$ advento da referida Lei, vem prestigiar o princípio constitucional da liberdade de iniciativa privada, o qual se encontra fundamentado no art. 170 da Constituição Federal de 1988, in verbis:

Art. 170. A ordem econômica, fundada na valorização do trabalho humano e na livre iniciativa, tem por fim assegurar a todos existência digna, conforme os ditames da justiça social, observados os seguintes princípios:

[...]

IX - tratamento favorecido para as empresas de pequeno porte constituídas sob as leis brasileiras e que tenham sua sede e administração no País. Parágrafo único. É assegurado a todos o livre exercício de qualquer atividade econômica, independentemente de autorização de órgãos públicos, salvo nos casos previstos em lei.

Parágrafo único. É assegurado a todos o livre exercício de qualquer atividade econômica, independentemente de autorização de órgãos públicos, salvo nos casos previstos em lei.

A respeito do princípio da liberdade de iniciativa, assevera Fábio Ulhoa Coelho: 
A liberdade de iniciativa é elemento essencial do capitalismo; quero dizer, do próprio modo de produção e não somente de sua ideologia. Diferentemente da igualdade e da fraternidade, valores com os quais compôs o mais conhecido slogan revolucionário, a liberdade não é apenas uma palavra de ordem que poderia, depois da vitória sobre a ordem feudal, ser olvidada. O capitalismo depende, para funcionar com eficiência, de um ambiente econômico e institucional em que a liberdade de iniciativa esteja assegurada. (COELHO, 2012 p 28).

Nesse sentido, a Lei no $12.441 / 11$ confere ao empresário a liberdade de constituir, individualmente, uma empresa com responsabilidade limitada, resguardando o patrimônio particular da expropriação de possíveis credores.

\section{NATUREZA JURÍDICA}

Quanto à natureza jurídica da empresa individual de responsabilidade limitada, a doutrina divide opiniões. Enquanto uma parte da doutrina defende que a EIRELI é um atributo imputado à pessoa natural na qualidade de empresária, outra insiste em afirmar que se trata de um novo tipo societário, restando ainda quem defenda a natureza jurídica sui generis do referido instituto.

Rubens Requião filiou-se a corrente doutrinária, que considera a pessoa natural, o titular de uma Empresa Individual de Responsabilidade Limitada:

Não se trata, com o novo estatuto atribuído a pessoa natural que assume a condição acima referida, de um novo tipo societário, como foi o caso quando da criação das empresas públicas e da subsidiária integral, que romperam o requisito da multiplicidade de sócios para formar a entidade. Mas apenas se imputa à pessoa natural empresária um novo atributo, qualificado pela responsabilidade limitada ao capital que destacar para a sua atividade, 
no que se distingue do empresário individual, que sofre responsabilidade ilimitada pelas suas obrigações. Esta última categoria, aliás, tenderá a desaparecer, como ocorreu com as sociedades de responsabilidade ilimitada, superadas pelas sociedades de responsabilidade ilimitada e pelas sociedades por ações. (RUBENS, 2012, p. 113).

Sobre a classificação da EIRELI o CONCLA, define:

230-5 - Empresa Individual de Responsabilidade Limitada (de Natureza Empresária)

Esta Natureza Jurídica compreende: - a Empresa Individual de Responsabilidade Limitada (Eireli), cuja natureza seja empresária (não-simples), prevista na Lei no. 12.441, de 11/07/2011. (COMISSÃO NACIONAL DE CLASSIFICAÇÃO, 2012).

Por outro lado, Fábio Ulhoa Coelho defende que a EIRELI trata-se de uma sociedade unipessoal, nos seguintes termos:

Juridicamente, a "empresa individual de responsabilidade limitada" (EIRELI) não é um empresário individual. Trata-se da denominação que a lei brasileira adotou para introduzir, entre nós, a figura da sociedade limitada unipessoal, isto é, a sociedade limitada constituída por apenas um sócio. (COELHO, 2012, p. 43).

Acrescenta, ainda, o autor sobre a figura do sócio:

O sócio único da EIRELI, como todos os sócios de sociedades empresárias, não é empresário. Empresário é a pessoa jurídica da EIRELI. Ela é o sujeito de direito que explora a atividade empresarial, contrata, emite ou aceita títulos de crédito, é a parte legitima para requerer a recuperação judicial ou ter a falência requerida e decretada. (COELHO, 2012, p. 44).

Já a Receita Federal (BRASIL) (2011) em nota, divulga:

A Eireli é uma pessoa jurídica de direito privado, com personalidade jurídica e patrimônio próprios, 
distintos e autônomos dos do empresário, titular único da empresa, que exerce profissionalmente atividade econômica organizada para a produção ou a circulação de bens ou serviços.

Desta forma, o titular da Empresa Individual de Responsabilidade Limitada não pode ser considerado um sócio, pois essa nova espécie de pessoa jurídica não corresponde a uma sociedade, como será demonstrado no art. 44 caput, do Código Civil com atual redação dada pela Lei em comento:

Art. 44. São pessoas jurídicas de direito privado:

I - as associações;

II - as sociedades;

III - as fundações.

IV - as organizações religiosas;

$\mathrm{V}$ - os partidos políticos. VI - as empresas individuais de responsabilidade limitada. (Incluído pela Lei no 12.441, de 2011).

Diante das opiniões apresentadas, surge o seguinte questionamento. Será o titular da EIRELI sócio ou empresário?

Surge então uma nova visão sobre o assunto, a qual defende a natureza jurídica sui generis da EIRELI.

Maria Tereza de Queiroz Piacentini (2011) define a expressão latina, afirmando que significa de "seu próprio gênero", ou seja, expressa que algo (fato, situação, caso) é único no gênero, é original, peculiar, singular, excepcional, sem semelhança com outro.

Nadialice Francischini de Souza (2011) argumenta em favor da natureza jurídica sui generis da EIRELI, nos seguintes termos:

Verifica-se que é requisito de existência da sociedade a pluralidade de pessoas. Sem este não há sociedade. Desta forma, o membro da Empresa Individual de Responsabilidade Limitada não pode ser considerado sócio, pois esse novo tipo de pessoa jurídica não é uma sociedade. 
Segundo a norma Portuguesa, o membro da EIRELI é o comerciante, é ele quem exerce a atividade empresarial, com o diferencial de sua responsabilidade ser limitada ao capital investido na atividade.

Contudo, no ordenamento brasileiro, o membro da EIRELI não pode ser considerado comerciante/ empresário, pois este é quem exerce diretamente a atividade empresarial, quem se responsabiliza pelos riscos da atividade, na melhor inteligência do artigo 966 do Código Civil pátrio que dispõe:

Art. 966. Considera-se empresário quem exerce profissionalmente atividade econômica organizada para a produção ou a circulação de bens ou de serviços.

Com a criação da Empresa Individual de Responsabilidade limitada, esta passa a ter status de pessoa jurídica, com capacidade, direitos e deveres distintos da pessoa que o compõe. Ou seja, é a EIRELI, devidamente constituída e registrada na Junta Comercial, quem vai exercer a atividade empresarial e assumir o risco da atividade. $\mathrm{O}$ membro da pessoa jurídica não exerce atividade, mas sim a pessoa jurídica.

Com base em todas essas observações, verifica-se que o membro da nova pessoa jurídica criada pela Lei n. 12.441/2011 não tem natureza jurídica nem de sócio, nem de empresário. Desta forma, somente resta concluir que este, no ordenamento brasileiro, tem natureza jurídica sui generis.

Em que pese, o dispositivo legal consista em estabelecer que a EIRELI seja uma pessoa jurídica de direito privado, surge com o advento do instituto essa celeuma.

\section{CONSIDERAÇÕES GERAIS SOBREA LEI NNo 12.441/2011}

\subsection{Titularidade}

A Lei que instituiu a EIRELI estabelece como seu titular a pessoa natural, desde que não haja impedimento legal. Deverá 
ser maior de 18 anos, brasileiro (a) ou estrangeiro (a) que se encontrar na livre administração de sua pessoa e bens ou menor emancipado, nas formas previstas pela legislação civil.

O texto legal é expresso no que tange a unicidade titular do empresário, art. 980-A do CC.

O Manual de Atos de Registro de Empresa de Empresa Individual de Responsabilidade Limitada, sobre o assunto instrui:

Pode ser titular de EIRELI a pessoa natural, desde que não haja impedimento legal:

a) maior de 18 anos, brasileiro(a) ou estrangeiro(a), que se achar na livre administração de sua pessoa e bens;

b) menor emancipado:

- por concessão dos pais, ou de um deles na falta de outro se o menor tiver dezesseis anos completos;

A outorga constará de instrumento público, que deverá ser inscrito no Registro Civil das Pessoas Naturais e arquivado na Junta Comercial.

- por sentença do juiz que, também, deverá ser inscrita no Registro Civil das Pessoas Naturais;

- pelo casamento;

- pelo exercício de emprego público efetivo (servidor ocupante de cargo em órgão da administração direta, autarquia ou fundação pública federal, estadual ou municipal);

- pela colação de grau em curso de ensino superior; e

- pelo estabelecimento civil ou comercial, ou pela existência de relação de emprego, desde que, em função deles, o menor com 16 anos completos tenha economia própria; (BRASIL,2011,p.12).

Quanto ao menor de 18 anos e maior de 16 anos, emancipado, poderá também constituir uma EIRELI, conforme orientação do Manual de Atos de Registro em consonância com o art. 5, Parágrafo Único, do Código Civil: 
A prova da emancipação do menor de 18 anos e maior de 16 anos, anteriormente averbada no registro civil, correspondente a um dos casos a seguir, deverá instruir o processo ou ser arquivada em separado, simultaneamente, com o ato constitutivo:

a) pela concessão dos pais, ou de um deles na falta do outro, mediante instrumento público, ou por sentença judicial;

b) casamento;

c) exercício de emprego público efetivo;

d) colação de grau em curso de ensino superior;

e) estabelecimento civil ou comercial ou pela existência de relação de emprego, desde que, em função deles, o menor com 16 anos completos tenha adquirido economia própria. (BRASIL, 2011, p.12).

Por fim, quanto aos impedimentos, não pode ser titular de EIRELI a pessoa jurídica, bem como a pessoa natural impedida por norma constitucional ou por lei especial.

\subsection{Integralização do capital}

Sobre a integralização do capital pela empresa individual de responsabilidade limitada a Lei é expressa em estabelecer no art. 980-A, caput, do CC, que não será inferior a 100 (cem) vezes o maior salário-mínimo vigente no país, in verbis:

Art. 980-A. A empresa individual de responsabilidade limitada será constituída por uma única pessoa titular da totalidade do capital social, devidamente integralizado, que não será inferior a 100 (cem) vezes o salário-mínimo vigente no país.

Fábio Ulhoa Coelho (2012, p.204) a respeito da integralização do capital, expõe que este deve estar totalmente integralizado na constituição, ou seja, não havendo a hipótese de capital subscrito não integralizado, os credores jamais poderão, em caso 
de falência, demandar a responsabilização do único sócio da EIRELI em seu patrimônio pessoal.

Assim, segundo o autor:

Haverá transferência da propriedade do bem, que separa-se do patrimônio da pessoa natural e passa à pessoa jurídica do empresário individual de responsabilidade limitada, com identificação e separação dos bens segregados, mediante ato formal como que o vincule a nova pessoa jurídica. (REQUIÃO, 2012, p. 114-115).

O capital social representa a garantia dos credores da empresa individual de responsabilidade limitada.

Verificados os pressupostos do art. 50 do CC, quais sejam, desvio de finalidade e confusão patrimonial, ocorrerá à desconsideração da personalidade jurídica, nos mesmos moldes da sociedade limitada.

De acordo com Rubens Requião (REQUIÃO, 2012, p. 116), a negligência na segregação do patrimônio e na operação da pessoa jurídica do empresário individual de responsabilidade limitada poderá incidir no art. 50 do Código Civil, que prevê a superação da personalidade jurídica por desvio de finalidade ou confusão patrimonial. Este tipo de pessoa jurídica não é uma autorização para prática de abusos, causando prejuízos aos credores e obrigações tributárias. Violada a boa-fé que deve orientar os negócios desta entidade, a desconsideração da personalidade jurídica provê meios para reprimir a prática e corrigir os prejuízos que causar, no caso levantando a limitação da responsabilidade.

Conforme a Ação Direta de Inconstitucionalidade $\mathrm{n}^{\circ}$ 4637, o salário mínimo é considerado inconstitucional como indexador do capital a ser integralizado (ADI 4637, 2011):

O capital social não poderá ser inferior a 100 (cem) vezes o maior salário mínimo vigente no País. Consideramos que tal requisito deve ser observado apenas na ocasião de sua constituição, de modo 
que o capital social não tenha que ser aumentado anualmente para acompanhar o salário-mínimo em vigor no futuro. Além disso, o dispositivo legal utiliza o termo "maior", sendo que não temos apenas o salário-mínimo federal, mas estaduais por exemplo. A cada ano o Departamento Nacional de Registro do Comércio - DNRC informará o maior salário-mínimo em vigor no país? Outra indagação é se tal limite representa o capital mínimo a ser integralizado no ato (e.g. capital subscrito de $\mathrm{R} \$$ 100 mil, [1] O PPS (Partido Popular Socialista) questiona esse limite por meio da ADI 4637 (Rel. Min. Gilmar Mendes). Alegou-se a impossibilidade de indexação ao salário-mínimo, além do limite quantitativo fixado não possuir qualquer razoabilidade, violando a livre iniciativa. [2] No âmbito federal, o salário-mínimo de 2011 é de $\mathrm{R}$ \$ 545,00, com a Lei $12.382 / 11$ prevendo os mecanismos de reajuste do mesmo até 2015 .

Rubens Requião (2012, p.114) leciona sobre o fato de o capital ser calculado em salários mínimos, tendo este seu valor aumentado, o empresário não terá que ajustar o seu capital. A lei exige a integralização do capital no momento do registro da empresa, o que poderá ocorrer por destaque de dinheiro ou de bens e qualquer espécie, exemplificativamente, instrumentos profissionais.

\subsection{Nome empresarial}

Semelhantemente ao que ocorre na Sociedade Limitada (Ltda), a Empresa Individual de Responsabilidade limitada (EIRELI), também poderá ser uma firma ou denominação.

Rubens Requião (2012, p.116) leciona que a lei admite que o empresário individual de responsabilidade limitada intitule-se por meio de uma firma ou por uma denominação, seguidas da expressão "EIRELI", uma concentração do nome legal da nova unidade jurídica.

Na mesma linha, Fábio Ulhoa Coelho sobre o assunto, 
preconiza que: "Na formação do nome empresarial seja firma ou denominação, em vez da locução "limitada”, deve-se acrescentar a sigla EIRELI."

\subsection{Constituição originária e superveniente}

A constituição da pessoa jurídica de direito privado, na nova modalidade prevista pelo ordenamento jurídico, poderá ocorrer de duas formas, sendo essas a constituição originária e a constituição superveniente.

Entende-se por constituição originária aquela que ocorre no inicio das atividades empresariais e a constituição superveniente a que advém das atividades empresariais já em curso.

Segundo Fábio Ulhoa Coelho (2012, p. 204), como qualquer sociedade limitada, a EIRELI pode constituir-se pela assinatura, por seu único titular, do ato constitutivo (CC, art. 980-A, caput) ou mediante transformação de registro de empresário individual (art. 968,§ 3), podendo também ser constituída pela concentração das quotas sob a titularidade de uma só pessoa, conforme previsão do (art. 980-A, § 3).

Leciona Rubens Requião (2012, p.117), que a alteração do art. 1.033 do Código Civil, a Lei no 12.441/2011 permite que sociedades que tenham perdido a multiplicidade de sócios se transformem em empresário individual ou em empresa individual de responsabilidade limitada, incidindo assim a modalidade de constituição superveniente.

Neste sentido, afirma Marcelo Siqueira

A EIRELI pode resultar da transformação de outro tipo societário (sendo sempre uma sociedade empresária), como uma sociedade limitada que passe a ter apenas um sócio (parágrafo único do art. 1.033 do Código Civil) - que pode até mesmo ser precedida de uma cisão -, mas em decorrência da utilização do termo quotas, nossa interpretação é de que a EIRELI não poderá resultar de sociedades por ações; 
O Manual de Atos de Registro de Empresa Individual de Responsabilidade Limitada, em relação à constituição da EIRELI, versa nos seguintes termos:

Do ato constitutivo da Empresa Individual de Responsabilidade Limitada constituída apenas por pessoa natural deverá constar, também, cláusula com a declaração de que o seu titular não participa de nenhuma empresa dessa modalidade. (BRASIL, 2011, p.8).

Neste diapasão, Rubens Requião (2012, p.115) afirma que a pessoa natural que constituir a empresa individual de responsabilidade limitada apenas poderá figurar somente em uma unidade desta natureza, conforme previsão do art.980-A, $\S 22^{\circ}$, acrescentado pela Lei no $12.441 / 2011$. Não poderá atuar, simultaneamente, duas empresas daquela espécie. Entretanto, sucessivamente poderá fazê-lo, desde que encerre formalmente a primeira empresa.

Em outras palavras, Fábio Ulhoa Coelho (2012, p.204) contribui com lição anteriormente apresentada, que se o único sócio da EIRELI for uma pessoa física, ela não poderá participar de outra sociedade unipessoal, mas poderá, porque não há vedação legal, ser sócio de limitadas pluripessoais ou mesmo de sociedade de modalidade diversa.

Cabe acrescentar que o ato constitutivo deverá indicar com precisão e clareza as atividades a serem desenvolvidas pela empresa, sendo vedada a inserção de termos estrangeiros, exceto quando não houver termo correspondente em português ou já incorporado ao vernáculo nacional (BRASIL, 2011, p. 15).

\subsection{Administração da empresa}

$\mathrm{O}$ art.980-A, § 6º determina que se apliquem ao empresário individual de responsabilidade limitada as regras próprias da sociedade limitada.

Nesse aspecto, destaca-se a possibilidade da administração da EIRELI ser exercida por uma ou mais pessoas designadas no 
ato constitutivo, conforme disposição do art. 1.060 do Código Civil.

Segundo o Manual de Atos de Registro da EIRELI (2011, p.16) não há obrigatoriedade de previsão de prazo do mandato de administrador, que, não estando previsto, entender-se-á ser de prazo indeterminado.

Não será exigida também a apresentação do termo de posse de administrador nomeado, quando do arquivamento do ato de sua nomeação.

A EIRELI poderá ser administrada pelo titular e/ou por não titular.

O administrador não titular considerar-se-á investido no cargo mediante aposição de sua assinatura no ato constitutivo em que foi nomeado.

A declaração de inexistência de impedimento para o exercício de administração, se não constar do ato constitutivo, deverá ser apresentada em ato separado, que instruirá o processo.

Conforme disposto no art. 1.172 do Código Civil, o administrador, não será designado de "gerente", pois possuem atribuições distintas.

\section{COMPATIBILIDADE COM MICROEMPRESA E EMPRESA DE PEQUENO PORTE}

A Empresa Individual de Responsabilidade Limitada é compatível com a Microempresa e com a Empresa de Pequeno Porte.

Primeiro aspecto a ser tratado, diz respeito à definição dessas duas espécies empresariais.

Sobre a classificação em Microempresa e Empresa de Pequeno Porte, assevera Rubens Requião:

De acordo com a Lei Complementar no 123/ 2006 (art.3), consideram-se microempresas a sociedade empresária, a sociedade simples, o empresário a que se refere o art. 966 da Lei no 10.406/2002 - o 
Código Civil - ou entidade equiparada a esses tipos, devidamente registrados no Registro de Empresas Mercantis ou no Registro Civil de Pessoas Jurídicas, que aufira, a cada ano calendário, receita bruta igual ou inferior a $\mathrm{R} \$ 240.000,00$. Já empresas de pequeno porte serão a sociedade empresária, a sociedade simples, o empresário a que se refere o art. 966 do Código Civil, ou entidade equiparada a esses tipos, que aufira, em cada ano-calendário, receita bruta superior a $R \$ 240.000,00$ e igual e inferior a $\mathrm{R} \$ 2.400 .000,00 . \mathrm{O}$ art. $3^{\circ}$, $\S 1^{\circ}$, da Lei Complementar $n^{\circ} 123 / 2006$ dá o conceito de renda bruta, composta do produto da venda de bens e serviços nas operações de conta própria, o preço dos serviços prestados e o resultado nas operações em conta alheia, não incluídas as vendas canceladas e os descontos incondicionais concedidos. (REQUIÃO 2012, p.90).

No que tange as atividades permitidas, o objeto não poderá ser ilícito, impossível, indeterminado ou indeterminável, ou contrário aos bons costumes, à ordem pública ou à moral.

Segue tabela exemplificativa de atividades que podem ser exercidas por uma EIRELI:

\begin{tabular}{|l|l|}
\hline Gêneros & Espécies \\
\hline Comércio & $\begin{array}{l}\text { veículos automotores } \\
\text { tratores, bebidas, armarinho }\end{array}$ \\
\hline Indústria & laticínios, confecções \\
\hline Serviços & $\begin{array}{l}\text { reparação de veículos automotores } \\
\text { transportes rodoviário de cargas }\end{array}$ \\
\hline
\end{tabular}

Apresentadas as causas de compatibilidade empresarial com o revolucionário instituto, vejamos uma causa de incompatibilidade. 


\section{INCOMPATIBILIDADE COM O EXERCÍCIO DA ADVOCACIA}

Com a introdução da Lei no $12.441 / 2011$, os profissionais da área advocatícia animaram-se com a possível constituição em EIRELI, no intuito de resguardar o patrimônio particular, e assim na qualidade de empresário, desfrutar dos benefícios fiscais conferidos a esta classe.

Realizadas diversas pesquisas no sentido de encontrar fundamento plausível para a transformação de uma sociedade de advogados em EIRELI, obteve-se uma resposta negativa.

Conforme art. 2, inc. XI, do Provimento 112/06 da OAB, o qual dispõe sobre as Sociedades de Advogados, verifica-se a impossibilidade de tal constituição, pois, prevê expressamente para as sociedades de advogados a responsabilidade subsidiária e ilimitada do sócio, in verbis:

Art. 2० O Contrato Social deve conter os elementos e atender aos requisitos e diretrizes indicados a seguir:

[...]

XI - é imprescindível a adoção de cláusula com a previsão expressa de que, além da sociedade, o sócio responde subsidiária e ilimitadamente pelos danos causados aos clientes, por ação ou omissão, no exercício da advocacia, assim como a previsão de que, se os bens da sociedade não cobrirem as dívidas, responderão os sócios pelo saldo, na proporção em que participem das perdas sociais, salvo cláusula de responsabilidade solidária; (ORDEM DOS ADVOGADOS DO BRASIL, 2006).

O Manual de Atos de Registro de Empresa Individual de Responsabilidade Limitada, aprovado pela Instrução Normativa No 117/2011, regulamenta sobre restrições e impedimentos para certas atividades: "É vedado o arquivamento na Junta Comercial de empresa cujo objeto inclua a atividade de advocacia". (BRASIL, 2011, p.8). 
Segundo Joana Neitsch (2011) a respeito da constituição da EIRELI por Profissionais Liberais, a lei define que esta modalidade empresarial, poderá prestar serviços de qualquer natureza. Contudo, o especialista em direito empresarial Alfredo de Assis Gonçalves Neto observa que há uma discussão, sobre a possibilidade de esse tipo de empresa poder ser utilizada para outras atividades, que não comerciais, como as intelectuais ou para o exercício da advocacia.

Destarte, conclui-se que o Advogado está impedido de constituir EIRELI.

\section{CONCLUSÃO}

A Lei $n^{\circ} 12.441 / 2011$ representa um avanço no ramo do direito empresarial, pois ao mesmo tempo em que garante autonomia ao empresário, possibilitando-o a gestão de seus negócios, individualmente, também proporciona proteção ao seu patrimônio pessoal.

Em que pese, a celeuma constatada em torno da natureza jurídica da modalidade empresarial, em um aspecto concordam, a EIRELI representa a redução da clandestinidade existente em muitas empresas de fato, com ausência de cobertura previdenciária, exposição a delitos tributários, entre outros riscos.

Cabe destacar, que a Lei é expressa em enquadrar a EIRELI como pessoa jurídica de direito privado, e que a confusão ocorre em detrimento da utilização do regramento da sociedade limitada no que couber.

Abstract: This paper discusses the innovations introduced by Law No. 12.441/11 to the Brazilian Civil Code, by inserting a new type of legal entity of private law, Individual Limited Liability Company (EIRELI). This law provides for the specific features of this institute, namely: ownership, the integration of the capital, the corporate name, the constitution and other formalities to be observed 
by the entrepreneur who wants to fit into this category and its administration. A novel classification revolutionizes the branch of business law as to divide opinions about their legal nature. Company Individual, Society Unipessoal or legal sui generis, the fact is that EIRELI represents an advance in the Brazilian legal system. Finally, it will address the compatibility of the institute with the Microenterprise (ME) and Small Company (EPP) and incompatibility with lawyerly activity.

Keywords: Business law. EIRELI. Individual company. Limited liability. Law No. 12.441/11.

\section{REFERÊNCIAS}

ADI 4637 - Ação Direta de Inconstitucionalidade (2011). Disponível em: http://www.stf.jus.br/portal/processo/verProcessoAndamento.asp?num $\underline{\text { ero }}=4637$ \& classe $=A D I \&$ origem $=A P \&$ recurso $=0$ \& tipoJulgamento $=M>$. Acesso em: 30 abr. 2012.

ANASTÁCIO, Rachel Bruno. Direito empresarial. Volume 08. Rio de Janeiro: Editora Lumen Juris, 2009.

BRASIL. Constituição (1988). Constituição da República Federativa do Brasil de 1988. Disponível em: <http://www.planalto.gov.br/ccivil_03/ constituicao/constitui\%C3\%A7ao.htm>. Acesso em 17 de jan. 2012.

BRASIL. Lei Federal no 12.441/2011. Disponível em: http://www. planalto.gov.br. Acesso em: 15 jan. 2012. Dispõe sobre a permissão para a constituição de empresa individual de responsabilidade limitada.

BRASIL. Ministério do Desenvolvimento, Indústria e Comércio Exterior. Manual de atos de registro de empresa individual de responsabilidade limitada - EIRELI. Brasília, 2011. Disponível em: <http://www.dnrc.gov.br/ Legislacao/IN\%20117\%202011.pdf>. Acesso em: 20 fev. 2012.

BRASIL. RECEITA FEDERAL. Nota cosit no 446. [Brasília], 2011. Disponível em: 〈http://www.irtdpjbrasil.com.br/EIRELI.COSIT.pdf〉. Acesso em: 20 fev. 2012.

BRASIL. Supremo Tribunal Federal. ADI questiona lei que permite criação de empresa individual de responsabilidade limitada. 12 ago. 2011. 
Disponível em: http://www.stf.jus.br/portal/cms/verNoticiaDetalhe. asp?idConteudo=186488> . Acesso em: 12 ago. 2012.

COELHO, Fábio Ulhoa. Manual de direito comercial: direito de empresa. 24. ed. São Paulo: Saraiva, 2012.

COELHO, Fábio Ulhoa. Princípios do direito comercial: com anotações ao projeto de código comercial. São Paulo: Saraiva, 2012.

COMISSÃO NACIONAL DE CLASSIFICAÇÃO. Natureza jurídica. Disponivel em: http://www.ibge.gov.br/concla/naturezajuridica/ descricao2009.1.php?id=2305. Acesso em: 12 ago. 2012.

EIRELI constituída por titular pessoa jurídica. 16 fev. 2012. Disponível em: <http://www.eireli.com/index.php/legislacao/15-geral/83-eireliconstituida-por-titular-pessoa-juridica>. Acesso em: 12 ago. 2012.

MARTINS, Sergio Renato Reolon. EIRELI Empresa Individual de Responsabilidade Limitada. 2012. Disponivel em: <http://www.crcrs.org.br/ arquivos/palestras

/110412_eireli.pdf>. Acesso em: 12 ago. 2012.

NEITSCH, Joana. A inovação nebulosa das Eirelis. Gazeta do Povo, 04 maio 2012. Disponível em: $\lfloor$ http://www.gazetadopovo.com.br/vidapublica/ justica-direito/conteudo.phtml?id=1250484>. Acesso em: 12 ago2012.

ORDEM DOS ADVOGADOS DO BRASIL (Bahia). Provimento No. 112/2006. Dispõe sobre as Sociedades de Advogados. 2006. Disponível em: <http://www.oab-ba.com.br/novo/Images/upload/File/ SociedadeDeAdvogados/LegislacaoEspecificaDasSociedadesDeAdvogados. pdf> Acesso em: 20 fev 2012.

PIACENTINI, Maria de Queiroz. Latinismo. Disponível em: http://www. Kplus.com.br/materia.asp?co=146\& rv=gramatica. Acesso em: 25 mar. 2012.

REQUIÃO, Rubens. Curso de direito comercial. 31. ed. ver. e atual. São Paulo: Saraiva, 2012. v. 1.

SANTOS, Diogo Jorge Favacho dos. Eireli nasce com questionamentos sobre seu alcance. Disponível em: < http://www.conjur.com.br/2011-ago-21/eirelinasce-questionamentos-relevantes-alcance $>$. Acesso em: 12 ago.2012.

SIQUEIRA, Marcelo. Empresa individual de responsabilidade limitada (EIRELI). Disponível em: 〈http://www.nbb.com.br/pub/societario10.pdf〉. Acesso em: 12 ago.2012. 
SOUZA, Nadialice Francischini de. Natureza juridica "sui generis" do membro da EIRELI. Disponível em : < http://www.direitonet.com.br/artigos/ exibir/7322/A-natureza-juridica-sui-generis-do-membro-da-EIRELI>. Acesso em: 12 ago.2012. 